\title{
REMOVAL OF HEAVY METALS FROM WATER BY WOOD-BASED LIGNOCELLULOCIS MATERIALS
}

\author{
BATRIC PESIC \\ Chemical and Materials Engineering Department, University of Idaho, USA
}

\begin{abstract}
Drinking water, particularly mine and industrial waters, may contain concentrations of heavy metals above the limits defined by the intended use. Therefore, hazardous heavy metals must be removed by water treatment, which in turn must satisfy the key criteria: to be efficient and inexpensive. The simplest method for treatment of mine and industrial waters is by chemical precipitation in the form of metal hydroxides. For treatment of drinking water, characterized by very low concentration of heavy metals, the adsorption on a solid support, such as activated carbon, is a common practice. The major deficiency of using activated carbon is the slow kinetics, low loading capacity, and high costs. For that reason, substantial research efforts are directed toward the use of natural sorbents, such as cellulose from wood. In this paper, the results will discuss the use of cellulose from wood for removal of cadmium from water of similar characteristics as drinking water. The other results will point to the treatment of water characterized with much higher concentrations of heavy metals, as found in mine waters. The adsorption studies were performed as a function of typical parameters: $\mathrm{pH}$, concentration, temperature, etc. To enhance the sorption capacity and kinetics, the cellulose molecules were modified by esterification, which was found highly beneficial. Regarding the source of cellulose, several wood species were examined. Among these, cottonwood consistently showed superior performance.

Keywords: absorption, cadmium, lead, mercury, copper, zinc, cellulose, kinetics.
\end{abstract}

\section{INTRODUCTION}

The common approach to treating the industrial waste waters is by chemical precipitation with calcium hydroxide. The resulting sludge is disposed onto a tailing pond, or stabilized for final disposal on the surface, or returned to the mine, if this was the original source. More expensive methods of treatment are activated carbon adsorption, ion exchange, membrane separation, electrolysis, coagulation/flocculation and chemical precipitation (other than hydroxide).

In this work, the treatment of waters contaminated with heavy metals has taken another approach, the adsorption by lignocellulosic materials in the form of wood sawdust. Cellulose is the most abundant natural, and renewable, biopolymer. It is present in the seed hairs of the cotton plant, but more abundantly, in combination with lignin and hemicellulose, in the cell walls of the woody plants. It is a straight chain polymer consisting of a large number of units. In wood, the other major components are hemicellulose (mixture of polysaccharides) and lignin. It contains plenty of hydroxyl and carboxylic groups as the providers of hydrogen bonding sites that enable long chain polymers to hold together. Lignin, an aromatic compound, provides structural strength, seals the water conduits, and prevents plant degradation. It also contains a variety of functional groups, such as hydroxyl, methoxyl, and carbonyl groups.

The sorption metal ions by lignocellulosic materials is generally described as adsorption, more precisely as biosorption. There are several major advantages of using biosorption for removal of heavy metals: effectiveness, low cost, minimization of chemical sludge, regeneration, no additional nutrients, and possibility for commercial metal recovery. The 
least expensive source of lignocellulosic materials is the plant wastes, such as sawdust from wood industry [1]-[3], bark [4], [5], rice husk [6], [7], straw [8], corn stalk [9].

The lignocellulosic materials can be used in their native, or modified form. The modification is performed to improve the sorption capacity for heavy metals. Two main approaches are (1) direct modification, and (2) grafting of cellulose. Direct modification of the cellulose is achieved by esterification, halogenation, oxidation, and etherification. Grafting modification involves a process in which side chain grafts are covalently attached to a main chain of a polymer backbone to form a branched copolymer.

In this work some results will be presented on adsorption of heavy metals on sawdust primarily from cottonwood. Most of cadmium adsorption studies by unmodified sawdust were performed from synthetic solutions. Because the effectiveness of adsorption of cadmium and other heavy metals $(\mathrm{Cu}, \mathrm{Zn}, \mathrm{Pb}$, etc.) on unmodified sawdust was too low, when mine waters were used, the sawdust modification by esterification had to be employed. The mine water samples came from actual Superfund mining sites, adding to the uniqueness of this work.

\section{MATERIALS AND METHODS}

\subsection{Materials}

Lignocellulosic materials were prepared by saw cutting of wood. In addition to cottonwood, sawdust from cedar, pine, fir and maple was prepared as well.

\subsection{Solutions}

Adsorption studies were performed with synthetic and real mine water solutions. Synthetic solutions were prepared by dissolving an aliquot amount of inorganic metal salt to produce desired concentration. Real mine waters were the samples from three Superfund sites in the USA, (1) Bunker Hill Mine, Berkeley Pit and Blackbird Mine. The composition of the main constituents is given in Table 1, which only lists the major heavy metals. Detailed composition of mine waters can be found in the EPA publications for Bunker Hill [10], Berkeley Pit [11], Blackbird Mine [12].

\subsection{Esterification}

Esterification of wood sawdust was accomplished according to the methods described by Head et al. [13], and the references cited within.

\subsection{Adsorption}

Adsorption was studied in a stirred reactor immersed in a temperature controlled water bath. Exact experimental conditions are annotated within the figures. In periodic time intervals, a solution sample was withdrawn for analysis by atomic absorption (Varian Spectra 10/20).

Table 1: Composition of mine waters with regard to the metals of interest.

\begin{tabular}{|l||l|l|l|}
\hline Metal (mg/L) & Blackbird Mine & Berkeley Pit & Bunker Hill \\
\hline \hline $\mathrm{Cu}$ & 123 & 185 & - \\
\hline $\mathrm{Co}$ & 26.7 & - & - \\
\hline $\mathrm{Zn}$ & - & 283 & 383 \\
\hline $\mathrm{Mn}$ & - & 29.6 & 225 \\
\hline
\end{tabular}




\subsection{Theoretical}

\subsubsection{Thermodynamics - adsorption isotherm}

In this work two most popular adsorption models were used, Langmuir [14] and Freundlich [15].

Langmuir derived the eqn (1) based on the following assumptions: (1) the adsorbent surface has fixed number of available sites, (2) all sites have the same energy (homogenous surface), (3) adsorption is in dynamic equilibrium (reversible), (4) no lateral interaction between adsorbed species:

$$
q_{e}=\frac{q_{m} K_{L} C_{e}}{1+K_{L} C_{e}}
$$

where $\mathrm{q}_{\mathrm{e}}(\mathrm{mg} / \mathrm{g})$ is the amount of adsorbate (cadmium) per unit of adsorbent (sawdust) at equilibrium, $\mathrm{q}_{\mathrm{m}}(\mathrm{mg} / \mathrm{g})$ is the amount of metal ions required to form a monolayer onto the adsorbent surface (maximum adsorption capacity), $\mathrm{K}_{\mathrm{L}}(\mathrm{L} / \mathrm{mg})$ is the Langmuir equilibrium constant, $\mathrm{C}_{\mathrm{e}}$ is the equilibrium concentration of adsorbate $(\mathrm{mg} / \mathrm{L})$. There are several ways to linearize eqn (1), an excellent analysis of each method is done by Tran et al. [16]. In this work, the linearized form of Langmuir eqn used is given in eqn (2):

$$
\frac{C_{e}}{q_{e}}=\frac{1}{K_{L} q_{m}}+\frac{1}{q_{m}} C_{e}
$$

Freundlich isotherm, an empirical equation, is relevant to the non-homogenous, i.e. heterogeneous, surfaces, eqn (3):

$$
q_{e}=K_{F} C_{e^{\frac{1}{n}}}
$$

where $\left.K_{F}(\mathrm{mg} / \mathrm{g}) \mathrm{L} / \mathrm{mg}\right)^{1 / \mathrm{n}}$ is the Freundlich constant and $1 / \mathrm{n}$ (dimensionless; $0<\mathrm{n}<10$ ) is a Freundlich intensity parameter signifying the magnitude of the adsorption driving force, or surface heterogeneity. Higher n-value the more heterogeneous the surface is. For $n>10$, the adsorption is irreversible [16].

The linear form of Freundlich equation is given below,

$$
\log q_{e}=\log K_{F}+\frac{1}{n} \log C_{e}
$$

The adsorption can be governed by either physical or chemical adsorption mechanisms. Physical sorption (physisorption) reflects the weak interactions (van der Waals) between adsorbate and adsorbent surface, while the chemical adsorption (chemisorption) involves the chemical bonding. The free energy change, $8 \mathrm{G}^{0}$, of adsorption is given by:

$$
8 \mathrm{G}^{0}=8 \mathrm{H}^{0}-\mathrm{T} 8 \mathrm{~S}^{0}=-\mathrm{RT} \ln \mathrm{K}
$$

where $\mathrm{R}$ is the universal gas constant $\left(8.314 \mathrm{~J} \mathrm{~mol}^{-1} \mathrm{~K}^{-1}\right)$, $\mathrm{T}$ is the temperature $(\mathrm{K})$, and $\mathrm{K}$ is the adsorption equilibrium constant. Eqn (5) can be rewritten in the form of Van't Hoff equation, eqn. (6):

$$
\ln K=\frac{-\Delta H^{0}}{R} \times \frac{1}{T}+\frac{\Delta S^{0}}{R}
$$

Variation of equilibrium constant of adsorption as a function of temperature can be utilized for determination of enthalpy $\left(8 \mathrm{H}^{0}\right)$ and entropy $\left(8 \mathrm{~S}^{0}\right)$ of adsorption. 


\subsubsection{Kinetics of adsorption kinetics}

The adsorption reaction mechanisms were explored by employing several reaction rate models, as presented below.

Pseudo-first order model is given in eqn (7),

$$
\frac{d q_{t}}{d t}=k_{1}\left(q_{e}-q_{t}\right)
$$

Solution of eqn (7) is:

$$
\ln \left(q_{e}-q_{t}\right)=\ln q_{e}-k_{1} \mathrm{t}
$$

Pseudo-second order model is represented by eqn (9),

$$
\frac{d q_{t}}{d_{t}}=k_{2}\left(q_{e}-q_{t}\right)^{2},
$$

the solution of which can be represented in the following form, eqn (10),

$$
\frac{t}{q_{t}}=\frac{1}{k_{2} q_{e}^{2}}+\frac{1}{q_{e}} t
$$

where $\mathrm{q}_{\mathrm{e}}$ has the same meaning as given above (amount of adsorbate at equilibrium; $\mathrm{mg} / \mathrm{g}$ ), and $\mathrm{q}_{\mathrm{t}}$ is the amount of adsorbate per mass of adsorbent $(\mathrm{mg} / \mathrm{g})$ at time, $\mathrm{t}$.

Intraparticle diffusion model [17] was proposed for adsorption processes controlled by diffusion within the porous adsorbent, like activated carbon, according to which the uptake varies proportionally with $\mathrm{t}^{1 / 2}$, eqn (11):

$$
q_{t}=k_{i d} t^{1 / 2}+\text { const }
$$

where, $\mathrm{k}_{\text {id }}\left(\mathrm{mg} / \mathrm{g} \min ^{1 / 2}\right)$ is the intraparticle diffusion rate constant.

\section{RESULTS AND DISCUSSION}

\subsection{Adsorption of heavy metals by unmodified sawdust}

\subsubsection{Adsorption of cadmium}

Cadmium adsorption was studied from synthetic solutions. The main adsorption parameters examined were $\mathrm{pH}$, cadmium concentration and temperature.

Effect of $p H$ : Cadmium adsorption results as a function of initial $\mathrm{pH}$ are given in. Fig. 1. It can be clearly seen that the initial $\mathrm{pH}$ has a significant effect on the rate and equilibrium of $\mathrm{Cd}$ adsorption. According to Fig. 1, the percent of $\mathrm{Cd}$ adsorption increases significantly with the increase of $\mathrm{pH}$. This consistent with the findings by numerous other researchers [18]-[21], to list a few. Invariably, the increase of Cd uptake by increase of $\mathrm{pH}$ is commonly assigned to the competitive adsorption of $\mathrm{H}^{+}$cation, which is more abundant at lower $\mathrm{pH}$. Complexation of cadmium by carbonyl $(\mathrm{C}=\mathrm{O})$, or hydroxyl $(\mathrm{OH})$ groups, is another possible mechanism for cadmium uptake, Taty-Costodes et al. [21].

It is important to note that the cadmium adsorption resulted in simultaneous $\mathrm{pH}$ increase. Bozic et al. [22] were the first to raise the absence of literature discussions on the mechanisms leading to $\mathrm{pH}$ change during adsorption. They have pointed out the importance of ion exchange mechanisms in adsorption by lignocellulosic materials, led by the results from another research group [23], [24]. The primary candidates for exchange with $\mathrm{H}^{+}$and $\mathrm{Cd}^{2+}$ in solution are $\mathrm{Ca}^{2+}$ and $\mathrm{K}^{+}$within the matrix of the solid sawdust. 


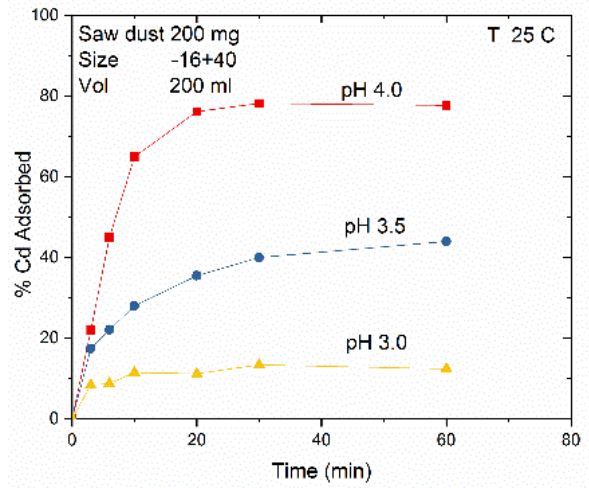

Figure 1: Effect of $\mathrm{pH}$ on $\mathrm{Cd}$ adsorption by cottonwood sawdust.

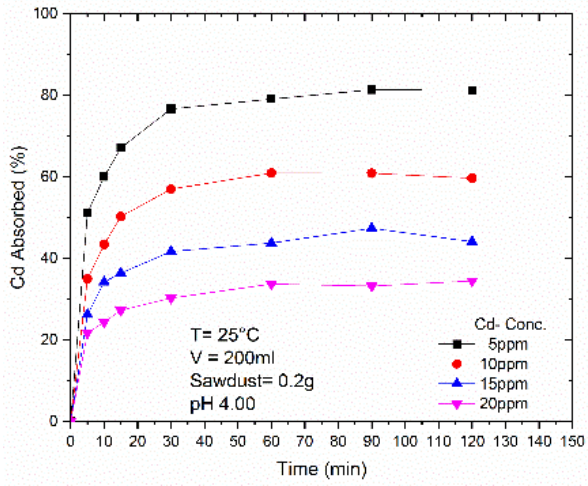

Figure 2: Effect of $\mathrm{Cd}$ concentration on adsorption by cottonwood sawdust.

Effect of cadmium concentration: The results from studies of this parameter provide the thermodynamic and the kinetic information. Initial cadmium concentration effect at $\mathrm{T} 25 \mathrm{C}$ is given in Fig. 2. Four different initial cadmium concentrations were used, $5 \mathrm{mg} / 1,10 \mathrm{mg} / \mathrm{l}$, $15 \mathrm{mg} / \mathrm{l}$ and $20 \mathrm{mg} / \mathrm{l}$. It is evident that the cadmium adsorption rate was relatively fast for all studied concentrations, as it took less than an hour to reach the equilibrium.

From the kinetic point of view, cadmium adsorption followed the pseudo-second order model, as $\mathrm{t} / \mathrm{q}_{\mathrm{t}} \mathrm{vs} \mathrm{t}$, eqn (10) was linear, for the results from both, $\mathrm{pH}$ and concentration effect. The linear fits produced correlation coefficients, $\mathrm{R}^{2}$, better than 0.995 . Regular first order kinetics, pseudo-first order (eqn (8)) and intraparticle diffusion (eqn (11)) did not produce satisfactory results.

Effect of temperature: Effect of temperature was studied at $25 \mathrm{C}, 35 \mathrm{C}$ and $45 \mathrm{C}$. The results presented in Fig. 3 show that temperature has little effect on the adsorption within the equilibrium stage. This parameter will be re-examined in the later study with the emphasis on the rate of adsorption during the initial kinetic stages, which will require sampling within first ten minutes of adsorption.

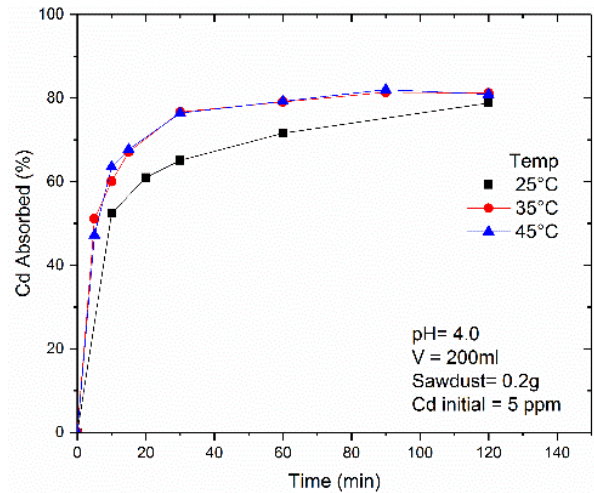

Figure 3: Temperature effect on $\mathrm{Cd}$ adsorption by cottonwood sawdust.

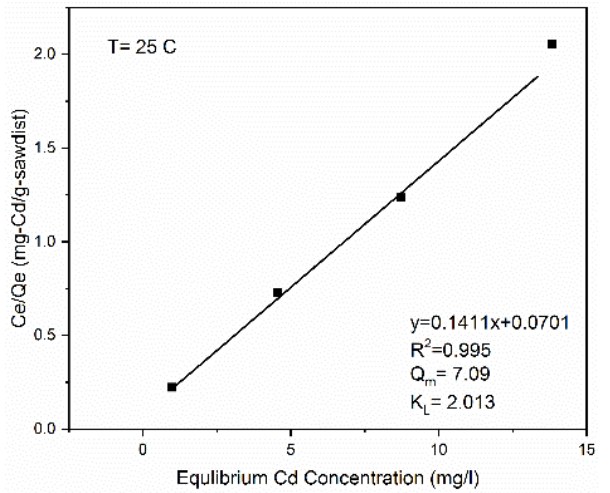

Figure 4: Linearization of Langmuir adsorption isotherm for $\mathrm{T}=25 \mathrm{C}$. 
Adsorption isotherm for cadmium adsorption.: The adsorption isotherm is of fundamental and practical importance as it reveals the mechanistic features of adsorption (monolayer versus multilayer), the surface heterogeneity, the interaction between the adsorbate and adsorbent. For practical purpose, the adsorption isotherm provides the information on the loading capacity of adsorbent.

Langmuir type of adsorption produced the best correlation $\left(\mathrm{R}^{2}\right.$ values higher than 0.995$)$ between the experimental and theoretical data, Fig. 4. The Langmuir equilibrium constants, $\mathrm{K}_{\mathrm{L}}$, was 2.013 and maximum uptake of cadmium, $\mathrm{q}_{\mathrm{m}}$, of sawdust was $7.09 \mathrm{mg}-\mathrm{Cd} / \mathrm{g}-$ sawdust.

Adsorption of heavy metals on different species of wood. Cellulose source from different species of wood were examined by using sawdust from cedar, fir, cottonwood and maple trees. The results are given in Fig. 5 and Fig. 6 with respect to adsorption of mercury and lead, respectively.

Adsorption of $\mathrm{Hg}^{2+}$, as $\mathrm{HgCl}_{2}$, on sawdust from various species of wood is presented in Fig. 5. It can be observed that the kinetics of $\mathrm{Hg}^{2+}$ adsorption was fast, requiring only about 10-15 minutes to achieve the equilibrium. About $70 \%$ of $\mathrm{Hg}^{2+}$ was absorbed by fir. The extent of adsorption on cottonwood and pine was only about $50 \%$. It is interesting to note that cedar was desorbing initially adsorbed mercury as the time progressed. The reasons for desorption presently are not known.

Results from adsorption of $\mathrm{Pb}^{2+}$, as $\mathrm{PbCl}_{2}$, are given in Fig. 6. Adsorption of lead was also fast. Cottonwood performed the best, close to $70 \%$, while pine had the lowest extent of adsorption, less than $40 \%$ of lead adsorption.

Cadmium adsorption was the least effective, Fig. 7, as the maximum extent of adsorption was on cottonwood, only about $40 \%$.

The adsorption of heavy metals on the species of wood presented here followed pseudosecond order of adsorption. An example of the linearization of eqn. (10) for pine and cottonwood are given in Fig. 8. An excellent linear fit with correlation coefficient $\mathrm{R}^{2}$ better than 0.999 was produced.

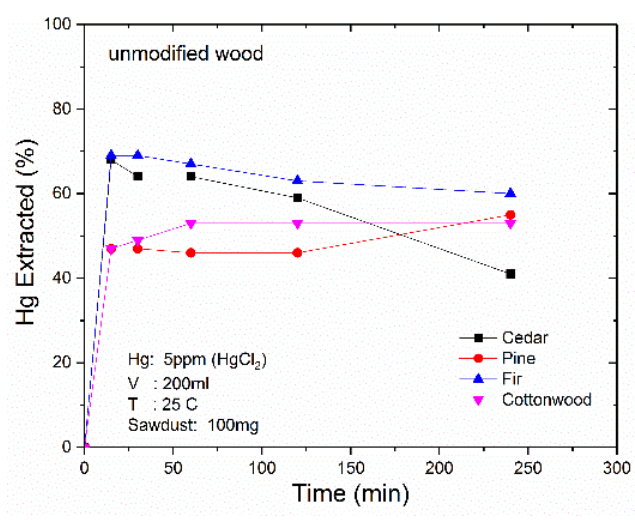

Figure 5: $\mathrm{Hg}^{2+}$ adsorption by sawdust from cedar pine, fir and cottonwood.

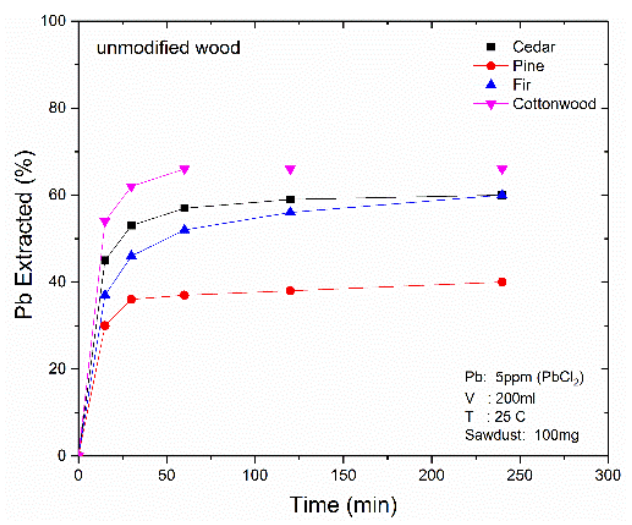

Figure 6: $\mathrm{Pb}^{2+}$ adsorption by sawdust from cedar pine, fir and cottonwood. 


\subsection{Adsorption on modified sawdust}

\subsubsection{Preliminary tests - search for effective esterification routes}

To achieve chemical modification, sawdust was treated with various reagents, such as acids $\left(\mathrm{HCl}, \mathrm{H}_{3} \mathrm{PO}_{4}\right.$, lignosulfonic acid) and basis $(\mathrm{NaOH})$, strong oxidizer $\left(\mathrm{H}_{2} \mathrm{O}_{2}, \mathrm{Br}_{2}\right)$, reducers $\left(\mathrm{NaBH}_{4}\right)$, and sulfidizers $\left(\mathrm{Na}_{2} \mathrm{~S}\right)$. The reasons for selection of these reagents varied. For example, $\mathrm{NaOH}$ was selected because of its well-known swelling capabilities, to improve the accessibility of wood matrix. Release of $\mathrm{OH}$ groups within the matrix would have a positive effect of retaining the heavy metals, most likely as hydroxides. $\mathrm{Na}_{2} \mathrm{~S}$ was selected for similar reasons. The effect of various reagents was studied mostly on cedar, cotton and cottonwood with respect to adsorption of $\mathrm{Hg}^{2+}, \mathrm{Pb}^{2+}$ and $\mathrm{Cu}^{2+}$. Only some selected data will be presented here. It was found that $\mathrm{Hg}^{2+}$ was always more difficult to remove from water than $\mathrm{Pb}^{2+}$. The best results for adsorption of $\mathrm{Hg}^{2+}$ were obtained when cottonwood was pretreated for 1-hour with $\mathrm{NaOH}$ (68\% removal) and $\mathrm{NaOH}+\mathrm{Br}_{2}$ ( $83 \%$ removal). Removal of $\mathrm{Pb}^{2+}$ under the same conditions was $100 \%$.

Method of employed modification has a very important role of establishing the efficiency for heavy metal removal by adsorption as can be readily seen in Fig. 9. In this figure, the $\mathrm{Cu}^{2+}$ adsorption results from several types of cottonwood modification are presented. It can be seen that unmodified wood responded with the lowest adsorption.

From this point on, it was decided to focus the attention on wood modification by esterification. Urea and phosphoric acid were selected as the reagents of choice to achieve the desired esterified wood product. In numerous experiments, it was found that the esterification with urea + phosphoric acid was quite sensitive on the conditions of esterification with respect to time, temperature and general handling of the wood. With respect to temperature, it appears that $130-135^{\circ} \mathrm{C}$ is the optimal range. Washing method and wash solution type were also important parameters.

The effectiveness of esterification was verified by the effectiveness of copper adsorption. The results in Fig. 10, clearly show that esterification under boiling conditions was much more extensive than the esterification under baking conditions, because the removal of copper was nearly $100 \%$ with the former.

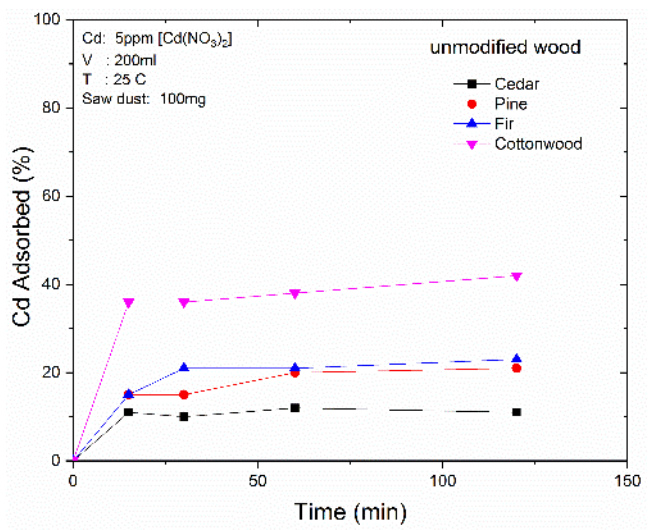

Figure 7: $\mathrm{Cd}^{2+}$ adsorption by sawdust from cedar, pine, fir and cottonwood.

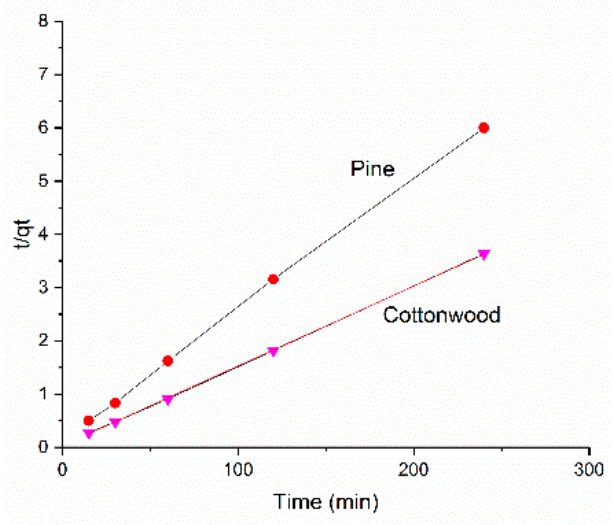

Figure 8: $\quad$ Pseudo-2 ${ }^{\text {nd }}$ order model for adsorption of lead on cottonwood and pine. 
One of the most detrimental ions with respect to its tendency to occupy the adsorption sites is iron. When designing a new ion exchange resin, or a solvent extractant, the ultimate test for the design success is its selectivity against iron. In the present case, it was found that esterified wood was not selective against iron at all as both ferrous and ferric iron were almost completely removed from the solutions under given conditions. However, the loading capacity of esterified wood appears to be high enough to accommodate both, $\mathrm{Cu}$ and $\mathrm{Fe}$, ions. In a practical application, because the concentration of iron in mine waters is orders of magnitude higher than the toxic heavy metals, iron would have to be removed in a preceding treatment step.

\subsubsection{Adsorption of heavy metals from actual mine waters}

Because of encouraging results in Fig. 9 and Fig. 10, it was decided to test the esterified wood with respect to its heavy metal adsorption capabilities from real mine waters. Due to a small amount of absorbent being used in adsorption experiments, $100 \mathrm{mg}$ per $100 \mathrm{ml}$ of solution, the original mine waters had to be diluted. The dilutions were $20 \mathrm{X}$ for water from Berkeley Pit Mine, 10X for Bunker Hill Mine and 10X for water from Blackbird Mine. All three mine waters are acidic in nature, but of different $\mathrm{pH}$. Knowing that the initial $\mathrm{pH}$ is the most important parameter to adsorption, to avoid the effect of $\mathrm{pH}$ all three waters were adjusted to the same initial value, $\mathrm{pH}=4$.

The adsorption of $\mathrm{Cu}, \mathrm{Zn}$ and $\mathrm{Mn}$ from Berkeley pit water is shown in Fig. 11. Copper removal was about $60 \%$, while $\mathrm{Zn}$ and $\mathrm{Mn}$ were removed to a lesser extent. The lower extraction values were due to the presence of large concentrations of other metals $(\mathrm{Fe}, \mathrm{Ca}$, $\mathrm{Al}, \mathrm{Mg}$, etc.) in this water. The $\mathrm{pH}$ change was from initial $\mathrm{pH} 4.06$ to final $\mathrm{pH} 3.78$.

The most significant elements in Bunker Hill Mine waters are Zn and Mn. About $60 \%$ of each metal was absorbed on esterified cottonwood within one hour, Fig. 12. As during the adsorption from Berkeley Pit Mine water, the $\mathrm{pH}$ of solution stayed about the same; $\mathrm{pH}=3.93$ was the final value.

Blackbird Mine is the only cobalt ore deposit in the USA. Now abandoned, the mine releases large concentrations of $\mathrm{Cu}(123 \mathrm{mg} / \mathrm{l})$ and $\mathrm{Co}(26.7 \mathrm{mg} / \mathrm{l})$ into adjacent water streams as tributaries to Salmon River. Removal of $\mathrm{Cu}$ and $\mathrm{Co}$ from Blackbird Mine water by esterified wood was very successful, with close to $100 \%$ efficiency, Fig. 13. pH of solution did not change during the adsorption.

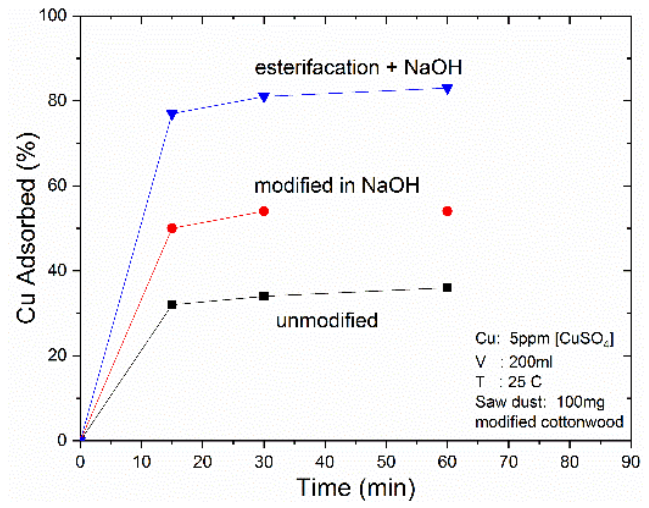

Figure 9: Importance and effectiveness of a method of esterification.

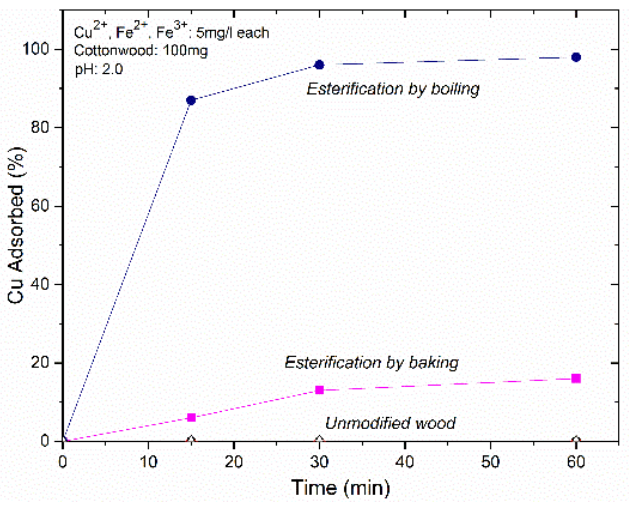

Figure 10: Adsorption of copper even in the presence of iron species. 


\subsection{Potential for practical application}

Excellent adsorption results and inexpensiveness of the natural-based-on-wood biosorbents open numerous pathways for development of methods for heavy metal removal from mine, and industrial, waters. One of the approaches would be to fill the porous bags with sawdust biosorbents for placement along the mine creek banks, or to use them as artificial water dams. Upon saturation, the bags would be replaced with those containing fresh adsorbent. The bags loaded with heavy metals could be disposed-of on the sites specifically designed for storage of hazardous waste. Or, the sawdust could be dried, and burned for recovery of particular heavy metals from the resulting ash.

Depending on conditions such as water composition, concentration, volume, terrain, etc. one could readily develop various other approaches for heavy metal removal, as long as the sorbent is efficient and inexpensive. Natural biosorbents are promising candidates toward that goal.

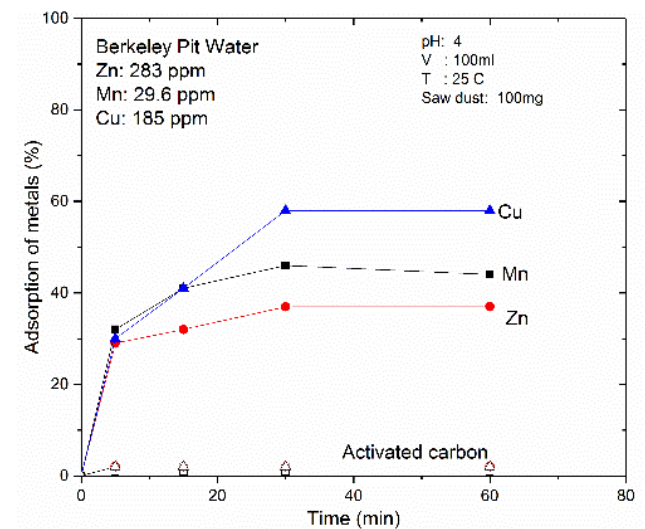

Figure 11: Removal of $\mathrm{Cu}, \mathrm{Mn}$ and $\mathrm{Zn}$ from Berkeley Pit water by adsorption on sawdust modified by esterification.

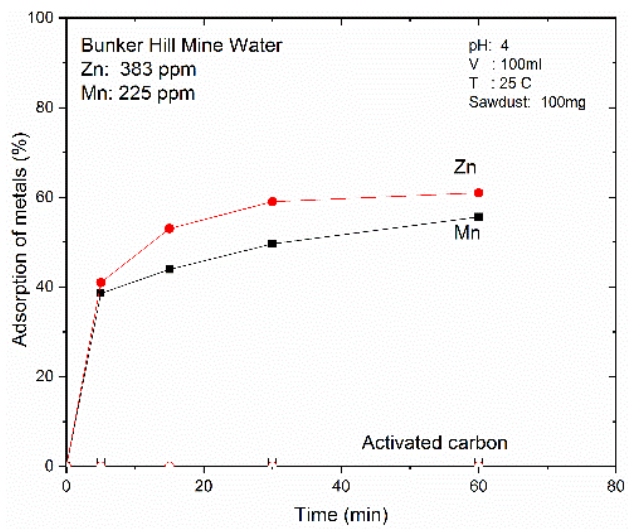

Figure 12: Removal of $\mathrm{Mn}$ and $\mathrm{Zn}$ from Bunker Hill water by adsorption on sawdust modified by esterification.

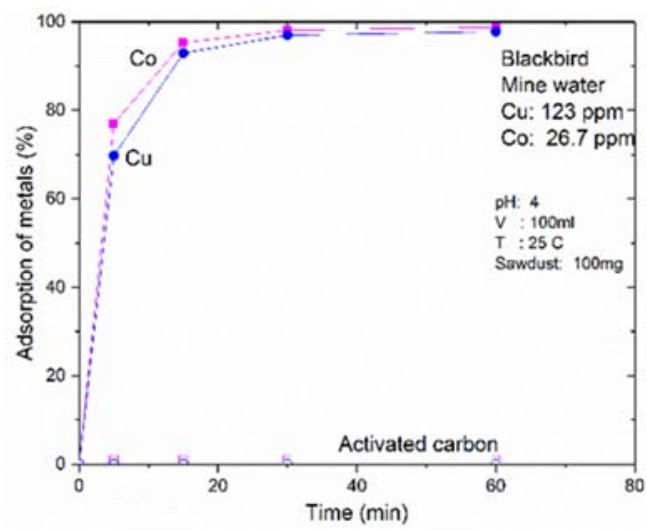

Figure 13: Removal of $\mathrm{Cu}$ and $\mathrm{Co}$ from Blackbird Mine water by adsorption on sawdust esterification modified. 


\section{CONCLUSIONS}

Wood in its native form is a heavy metal biosorbent. This property is derived from the presence of numerous hydroxyl groups on the cellulose backbone molecule. The hydroxyl groups are also present on two other main wood constituents, hemicellulose and lignin. Adsorption capabilities of wood materials can further be enhanced by chemical modification, such as esterification, by introduction of ion exchange, and/or chelating functional groups.

Thermodynamic and kinetic studies on adsorption of cadmium were done from synthetic solutions. The cellulose source was the sawdust from cottonwood. Initial $\mathrm{pH}$ of solution was an important parameter, as cadmium uptake increased by increase of $\mathrm{pH}$. Temperature was not an important parameter for the equilibrium of adsorption, but it was for the initial kinetics. Cadmium loading capacity of cottonwood was $7.09 \mathrm{mg}$ per gram of sawdust.

Native sawdust does not have good loading capacity for uptake of heavy metals from actual mine waters. However, upon modification by esterification, the kinetics and loading capacity dramatically improved, as verified by successful removal of $\mathrm{Cu}, \mathrm{Co}, \mathrm{Zn}$, and $\mathrm{Mn}$. For comparison purpose, activated carbon removed barely measurable amount of these metals. Esterification was achieved by phosphoric acid and urea mixture. Particular sequence of esterification is an important parameter.

Chemically modified wood offers a pathway for development of technologies for treatment of industrial waters and mitigation of mine sites.

\section{ACKNOWLEDGEMENTS}

The experimental help for adsorption of cadmium on cottonwood was provided by Burroughs, Brad J., as the undergraduate student in the department. Victor C. Storhok, a scientific aide at the time, was responsible for adsorption of heavy metals from mine waters.

\section{REFERENCES}

[1] Yea, J.H. et al., Effect of graft copolymerization of fir sawdust lignocellulose with $\mathrm{N}$-vinylpyrrolidone on adsorption capacity to tea catechins. Carbohydrate Polymers, 81, pp. 441-44, 2010.

[2] Emin Argun, M., Dursun, S., Ozdemir, C. \& Karatas, M., Heavy metal adsorption by modified oak sawdust: Thermodynamics and kinetics. Journal of Hazardous Materials, 141, pp. 77-85, 2007.

[3] Sciban, M., Klasnja, M. \& Skrbic, B., Modified softwood sawdust as adsorbent of heavy metal ions from water. Journal of Hazardous Materials, (B136), pp. 266-271, 2006.

[4] Harikishore, D., Reddy, K., Seshaiah, K., Reddy, A.V.R.M., Rao, M. \& Wang, M.C., Biosorption of $\mathrm{Pb} 2+$ from aqueous solutions by Moringa oleifera bark: Equilibrium and kinetic studies. Journal of Hazardous Materials, 174, pp. 831-838, 2010.

[5] Nehrenheim, E. \& Gustafsson, J.P., Kinetic sorption modelling of $\mathrm{Cu}, \mathrm{Ni}, \mathrm{Zn}, \mathrm{Pb}$ and $\mathrm{Cr}$ ions to pine bark and blast furnace slag by using batch experiments. Bioresource Technology, 99, pp. 1571-1577, 2008.

[6] Ye, H., Zhu, Q. \& Du, D., Adsorptive removal of $\mathrm{Cd}(\mathrm{II})$ from aqueous solution using natural and modified rice husk. Bioresource Technology, 101, pp. 5175-5179, 2010.

[7] Kumar, U. \& Bandyopadhyay, M., Sorption of cadmium from aqueous solution using pre-treated rice husk. Bioresource Technology, 97, pp. 104-109, 2006. 
[8] Chand, R., Watari, T., Inoue, K., Luitel, H.N., Torikai, T. \& Yada, M., Chemical modification of carbonized wheat and barley straw using HNO3 and the adsorption of Cr(III). Journal of Hazardous Materials, 167, pp. 319-324, 2009.

[9] Zheng, L., Dang, Z., Zhu, C., Yi, X., Zhang, H. \& Liu, C., Removal of cadmium(II) from aqueous solution by corn stalk graft copolymers. Bioresource Technology, 101, pp. 5820-5826, 2010.

[10] Phase 2 Testing Results Bunker Hill Mine Water Treatability Study, CH2M Hill, Contract No 68-W-98-228, November 2000.

[11] Berkeley Pit Final Report by Montana Tech of the University of Montana for US EPA, National Risk Management Research Laboratory Cincinnati, Ohio 45268, IAG ID. No. DW89935117-01-0, April 1997.

[12] US Environmental Protection Agency, EPA Superfund Record of Decision: Blackbird Mine EPA ID: IDD980725832 OU 01 Lemhi County, ID, 2003.

[13] Head, A.J., Kember, N.F., Miller, R.P. \& Wells, R.A., Ion exchange of modified cellulose. II. Recovery of thorium from monazite using cellulose phosphate. J. Appl. Chem., 9, pp. 599-608, 1959.

[14] Langmuir, I., The adsorption of gases on plane surfaces of glass, mica, and platinum. J. Am. Chem. Soc., 40, p. 1361, 1918.

[15] Freundlich, H.M.F., Over the adsorption in solution. Z. Phys. Chem., 57, p. 385, 1906.

[16] Tran, H.N., You, H-J. \& Chao, H-P., Thermodynamic parameters of cadmium adsorption onto orange peel calculated from various methods: A comparative study. J. Environ. Chem. Engng., 4, p. 2671, 2016.

[17] Weber, W.J. and Morriss, J.C., Kinetics of adsorption on carbon from solution. J. Sanit. Engng. Divi., 89(2), p. 31, 1963.

[18] Ebrahimi, A. Ehteshami, M. \& Dahrazma, B., Isotherm and kinetic studies for the biosorption of cadmium from aqueous solution by Alhaji maurorum seed. Proc. Safety and Environmental Protection, 98, pp. 374-382, 2015.

[19] Najam, R. \& Anrabi, S.M.A., Removal of cadmium from aqueous solutions by poplar sawdust: equilibrium and thermodynamic studies. Research and Reviews Journal of Chemistry, 3, Issue 4, pp. 9-17, 2014.

[20] Argun, M.E., Dursan, S., Ozdemir, C. \& Karatas, M., Heavy meal adsorption by modified oak sawdust-thermodynamics and kinetics. Journal of Hazardous Materials, 141, pp. 77-85, 2007.

[21] Taty-Costodes, V.C., Fauduet, H., Porte, C. \& Delacroix, A., Removal of Cd(II) and $\mathrm{Pb}$ (II) ions from aqueous solutions by adsorption onto sawdust of Pinus sylvestris. Journal of Hazardous Materials, (B105), pp. 121-142, 2003.

[22] Bozic, A., Stankovic, V., Gorgievski, M., Bogdanovic, G. \& Kovacevic, R., Adsorption of heavy metal ions by sawdust of deciduous trees. Journal of Hazardous Materials, 171, pp. 684-692, 2009.

[23] Villaescusa, I., Fiol, N., Martinez, M., Miralles, N., Poch, J. \& Serarols, J., Removal of copper and nickel ions from aqueous solutions by grape stalks wastes. Water Research, 38, pp. 992-1002.

[24] Fiol, N., Villaescusa, I., Martinez, M., Miralles, N., Poch, J. \& Serarols, J., Sorption of $\mathrm{Pb}(\mathrm{II}), \mathrm{Ni}(\mathrm{II}), \mathrm{Cu}$ (II) and $\mathrm{Cd}(\mathrm{II})$ from aqueous solution by olive stone waste. Separation and Purification Technology, 50, pp. 132-140, 2006. 